\title{
Five years of Dentistry 3000
}

Alexandre Rezende Vieira

Editor in Chief

Department of Oral Biology, University of Pittsburgh School of Dental Medicine, Pittsburgh PA, USA

Citation: Vieira AR. (2017) Five years of Dentistry 3000. Dentistry 3000. 1:a001 doi:10.5195/d3000.2017.81

Received: December 5, 2017

Accepted: December 12, 2017

Published: December 15, 2017

Copyright: (C2017 Vieira AR. This is an open access article licensed under a Creative Commons Attribution Work 4.0 United States License.

Email: arv11@pitt.edu
Dentistry 3000 is a journal published by the University Library System (ULS), University of Pittsburgh, as part of its D-Scribe Digital Publishing Program and is cosponsored by the University of Pittsburgh Press. In that capacity, we have created a journal that is free from the pressures of publishers, authors, funding agencies, and other interest groups. Dentistry 3000 has no publication fees for authors and is readily accessible to all via web. The main goal of the journal continues to be disseminating scientific information in dentistry, which is a field that suffers due to the limited number of journals interested in publishing a wide range of topics of dental research.

We have been encouraging young authors to submit their first scholarly works as a way to incentivize the development of and interest in academic and scholarly activities. We have also been supporting authors from smaller centers, facilitating the publication of their work. We provide help with manuscript preparation and improving language and style during the peerreview process. We believe these practices can only benefit the scientific community, and we have no concerns regarding specific individual agendas and misrepresented perceptions of quality. We do not measure Dentistry 3000 by impact factor, which in reality is a measure of the impact of the authors that publish in a particular journal. We understand that a small fraction of papers recieves many citations, whereas the vast majority of papers get few or none at all.

In the last five years, we have published over 40 papers. Our goal moving forward is to continue the practices we have established: fair and unbiased peer-reviews, with emphasis on content and findings rather than looking for reports with positive results. We aim to continue supporting young authors in publishing their first works and valuing all disciplines of dentistry equally.

We are looking forward to your future contributions to Dentistry 3000 .
(cc)BY

ULLS D-Sorte
New articles in this journal are licensed under a Creative Commons Attribution 4.0 United States License.

This journal is published by the University Library System, University of Pittsburgh as part of its D-Scribe Digital Publishing Program and is cosponored by the University of Pittsburgh Press. 